\title{
Impairment of the Rod Outer Segment Membrane Guanylate Cyclase Dimerization in A Cone-Rod Dystrophy Results in Defective Calcium Signaling ${ }^{\dagger}$
}

\author{
Teresa Duda, *, Venkateswar Venkataraman,, Anna Jankowska,,$\S$ Christian Lange," Karl-W. Koch," and \\ Rameshwar K. Sharma \\ The Unit of Regulatory and Molecular Biology, Departments of Cell Biology and Ophthalmology, SOM and NJMS, \\ University of Medicine and Dentistry of New Jersey, Stratford, New Jersey 08084, and Institut für Biologische \\ Informationverarbeitung, Forschungszentrum Jülich, Postfach 1913, D-52425, Germany
}

Received June 30, 2000

\begin{abstract}
Rod outer segment membrane guanylate cyclase1 (ROS-GC1) is the original member of the membrane guanylate cyclase subfamily whose distinctive feature is that it transduces diverse intracellularly generated $\mathrm{Ca}^{2+}$ signals in the sensory neurons. In the vertebrate retinal neurons, ROS-GC1 is pivotal for the operations of phototransduction and, most likely, of the synaptic activity. The phototransduction- and the synapse-linked domains are separate, and they are located in the intracellular region of ROS-GC1. These domains sense $\mathrm{Ca}^{2+}$ signals via $\mathrm{Ca}^{2+}$-binding proteins. These proteins are ROS-GC activating proteins, GCAPs. GCAPs control ROS-GC1 activity through two opposing regulatory modes. In one mode, at nanomolar concentrations of $\mathrm{Ca}^{2+}$, the GCAPs activate the cyclase and as the $\mathrm{Ca}^{2+}$ concentrations rise, the cyclase is progressively inhibited. This mode operates in phototransduction via two GCAPs: 1 and 2. The second mode occurs at micromolar concentrations of $\mathrm{Ca}^{2+}$ via $\mathrm{S} 100 \beta$. Here, the rise of $\mathrm{Ca}^{2+}$ concentrations progressively stimulates the enzyme. This mode is linked with the retinal synaptic activity. In both modes, the final step in $\mathrm{Ca}^{2+}$ signal transduction involves ROS-GC dimerization, which causes the cyclase activation. The identity of the dimerization domain is not known. A heterozygous, triple mutation -E786D, R787C, T788M- in ROS-GC1 has been connected with autosomal cone-rod dystrophy in a British family. The present study shows the biochemical consequences of this mutation on the phototransduction- and the synapse-linked components of the cyclase. (1) It severely damages the intrinsic cyclase activity. (2) It significantly raises the GCAP1- and GCAP2-dependent maximal velocity of the cyclase, but this compensation, however, is not sufficient to override the basal cyclase activity. (3) It converts the cyclase into a form that only marginally responds to $\mathrm{S} 100 \beta$. The mutant produces insufficient amounts of the cyclic GMP needed to drive the machinery of phototransduction and of the retinal synapse at an optimum level. The underlying cause of the breakdown of both types of machinery is that, in contrast to the native ROS-GC1, the mutant cyclase is unable to change from its monomeric to the dimeric form, the form required for the functional integrity of the enzyme. The study defines the CORD in molecular terms, at a most basic level identifies a region that is critical in its dimer formation, and, thus, discloses a single unifying mechanistic theme underlying the complex pathology of the disease.
\end{abstract}

Phototransduction is a biochemical process by which the vertebrate rods and cones generate electrical signals in response to captured photons (reviewed in refs 1 and 2). This process occurs in the rod (or cone) outer segments (ROS). ${ }^{1}$ The photon induces a decline in the level of cyclic GMP and closure of the cyclic GMP-gated cation channels. This results in a drop of intracellular $\mathrm{Ca}^{2+}$ from $\sim 500 \mathrm{nM}$ in darkadapted photoreceptor cell to below $100 \mathrm{nM}$ after illumina-

$\dagger$ This study was supported by USPHS awards HL 58151 (T.D.) and EY 10828 (R.K.S.); by the affiliated support of the Research to Prevent Blindness Inc., New York, and the Lions Eye Research Foundation, New Jersey.

* To whom all correspondence should be addressed: Phone: (856) 566-6976. Fax: (856) 566-7057. E-mail: dudatm@umdnj.edu.

$\doteqdot$ University of Medicine and Dentistry of New Jersey.

$\S$ On postdoctoral training from the Department of Radiobiology and Cell Biology, University of Medical Sciences, Swiecickiego 6, 60-781, Poznan, Poland.

"Institut für Biologische Informationverarbeitung. tion. This drop activates ROS guanylate cyclase (ROS-GC). Increased synthesis of cyclic GMP, concomitant with the inactivation of the phototransduction cascade, leads to the reopening of the cyclic GMP-gated channels and restoration of the dark current of the photoreceptors. Thus, two pivotal molecules, $\mathrm{Ca}^{2+}$ and cyclic GMP, are interlocked in a reciprocal feedback loop.

\footnotetext{
${ }^{1}$ Abbreviations: ANF-RGC, atrial natriuretic factor receptor guanylate cyclase; BSA, bovine serum albumin; cyclic GMP, guanosine 3',5'-cyclic-phosphate; $\mathrm{CNG}$ channel, cyclic nucleotide gated channel; CORD, cone-rod dystrophy; DTT, 1,4-ditiothreitol; EGTA, ethylene glycol bis ( $\beta$-aminoethyl ether)- $N, N, N^{\prime}, N^{\prime}$-tetraacetic acid; GCAP, guanylate cyclase activating protein; GTP, guanosine $5^{\prime}$-triphosphate; IPTG, isopropyl-1-thio- $\beta$-D-galactosidase; LCA, Leber's congenital amaurosis; ROS, rod outer segment; ROS-GC, rod outer segment membrane guanylate cyclase; PMSF, phenylmethylsulfonyl fluoride; SDS-PAGE, sodium dodecyl sulfate - polyacrylamide gel electrophoresis; wt-r, wildtype recombinant.
} 
There are two forms of ROS-GC, termed ROS-GC1 and ROS-GC2 (1). Both reside in photoreceptors and mimic the native cyclase activity under conditions of phototransduction; yet, only ROS-GC1 has been firmly linked with phototransduction. To date, (1) only ROS-GC1 presence in ROS has been demonstrated via its direct purification from ROS and its partial sequencing $(3,4)$; (2) mutations that cause loss of ROS-GC1 expression lead to defects in retinal morphology as well as visual transduction in human (5) and chicken (6); and (3) ROS-GC1 mutations specific to rod- or rod-cone specific abnormalities explain the disease phenotype in molecular terms (7-9).

ROS-GC represents a subfamily of membrane guanylate cyclases $(1,10)$. It distinguishes itself from the other subfamily of surface receptors in that it is not regulated by extracellularly generated signals. In contrast, it is modulated by intracellularly generated $\mathrm{Ca}^{2+}$ signals in the vertebrate sensory neurons of the retina and the pinealocytes $(1,11)$. It senses $\mathrm{Ca}^{2+}$ signals indirectly via $\mathrm{Ca}^{2+}$-binding proteins: GCAPs and $\mathrm{S} 100 \beta$. Consistent with the membrane guanylate cyclase family trait, both ROS-GC subfamily members are single transmembrane-spanning proteins, with an extracellular segment and an intracellular segment of almost equal length. A 26 amino acid transmembrane domain separates the two segments $(10,12-15)$. A modulatory feature of ROS-GC1, unique to itself, has started to emerge. ROS-GC1 responds to multiple $\mathrm{Ca}^{2+}$ signals, four of which have been recognized. One signal is mediated by GCAP1, this is linked with phototransduction (16-19); the second, also presumably linked with phototransduction, is mediated by GCAP2 (20$22)$; the third, linked with the retinal synaptic activity, is mediated by $\mathrm{S} 100 \beta(23-25)$. The fourth $\mathrm{Ca}^{2+}$ signal is mediated by neurocalcin (26). The physiological importance of this signal is not clear, however. Each signal is transduced by ROS-GC1 specific module. The $\mathrm{Ca}^{2+}$-sensing modules reside in the intracellular region of ROS-GC1 where in a signal-specific manner they individually control the core catalytic cyclase module. Phototransduction-linked, GCAP1signaling ROS-GC1 module has been mapped (27). It is composed of two domains: M445-L456, the transduction domain, and L503-I522, the binding domain (27). The GCAP2- and S100 $\beta$-modulated ROS-GC1 domains, which reside at the $\mathrm{C}$-terminal region of the cyclase, have not been mapped $(22,23,28)$. An intriguing regulatory feature of the phototransduction-linked and the retinal synapse-linked ROS$\mathrm{GC} 1$ modules is that they translate $\mathrm{Ca}^{2+}$ signals into the production of cyclic GMP in opposite fashions. The phototransduction-linked ROS-GC1 modules, at nanomolar concentrations of $\mathrm{Ca}^{2+}$ and in the presence of GCAPs, mediate activation of the cyclase and progressively inhibit it as the $\mathrm{Ca}^{2+}$ concentrations near the micromolar range. On the other hand, the micromolar ranges of $\mathrm{Ca}^{2+}$ progressively stimulate the cyclase via $\mathrm{S} 100 \beta$. Thus, the ROS-GC1 is precision machinery designed to sense and appropriately respond to $\mathrm{Ca}^{2+}$ signals, resulting in the enhanced or decreased production of cyclic GMP.

Very recent studies have started to indicate an important structural prerequisite of ROS-GC1, which is essential for its functional integrity. The cyclase must be in a dimeric form to be active $(29,30)$. The identity of the dimerization domain is not known.
Almost complete $(31)$ and partial structure $(32,33)$ of the ROS-GC1 gene has been elucidated. This information has allowed to link specific point mutations in the gene with several types of rod- and cone-associated abnormalities (3440). These abnormalities in extreme cases, such as Leber's congenital amaurosis (LCA1), cause blindness at birth, and in less severe cases, such as cone-rod dystrophy type 6 (CORD6), there is progressive deterioration in vision, ultimately, also leading to blindness. Several ROS-GC1 mutations spread over both extra- and intracellular domains of the protein have been detected in LCA1-afflicted patients (34-36). However, to date, only in the case of F514S mutation, the biochemical consequences have been determined and the disease phenotype has been explained in terms of altered ROS-GC1 function (7). Since this original finding, several similar investigations linking ROS-GC1 mutations with LCA1 and CORD6 have begun to emerge $(8,9)$.

In a newly identified CORD6 case, a heterozygous mutation of three amino acids, which are at adjacent positions -E786D, R787C, T788M- occurs in ROS-GC1 (37). This triple mutation results in dominant cone-rod dystrophy, which, in turn, leads to an early loss in the clarity of vision and color distinction. Progressive night blindness and deterioration in the peripheral visual field follow.

The objective of the present study was to determine at a biochemical and functional level the effect of the CORD6triple mutation - E786D, R787C, T788M (ERT $\rightarrow$ DCM)on the phototransduction and the retinal-synapse linked modules of ROS-GC1 and, thus, to define pathology of the disease in precise molecular terms. The findings demonstrate that the mutation strikingly alters the $\mathrm{Ca}^{2+}$-sensing machinery of these modules. In addition, at a most basic level, the study identifies a region in ROS-GC1 that is critical for dimer formation, providing a single unifying mechanistic theme underlying the complex pathology of the disease.

\section{MATERIALS AND METHODS}

Construction of ROS-GCl Mutant. The CORD-6 related triple mutation, ERT $\rightarrow$ DCM, was introduced into ROS-GC1 cDNA in pcDNA3 expression vector by "Quick Change" mutagenesis (Stratagene) according to the manufacturer's protocol. The mutated recombinant was sequenced to confirm its identity. The N-terminal FLAG (DYKDDDDK) epitope was inserted into the cDNA immediately after the signal peptide cleavage site as described previously $(3,7,8,10)$.

Expression and Purification of GCAP1 and GCAP2. The bovine GCAP1 cDNA was expressed in Escherichia coli ER2566 strain and purified to homogeneity as described in ref 7. The bovine GCAP2 cDNA was expressed in Sf9 insect cells and purified to homogeneity as described in refs 15 , 22, and 41 or in E. coli BL21(DE3)/pLysS strain as described below. The coding sequence of bovine GCAP2 was amplified from the clone GCAP2/pVL1393 by polymerase chain reaction (PCR) using the following primers: $5^{\prime}$-AAATTCCATATGGGGCAGCAGTTC (sense primer introducing an NdeI site encompassing the ATG start codon) and 5'GCCCCGAATTCATCAGAACATGGC (antisense primer an additional STOP codon and an EcoRI restriction site). The product was subcloned into the pET221a $(+)$ vector (Novagene) via the introduced restriction sites (15). The resulting plasmid was sequenced to confirm its identity. 
GCAP2 protein was expressed in an E. coli BL21(DE3)/ pLysS strain carrying the plasmid pBB131 (a kind gift of Dr. J. Gordon) encoding for yeast $N$-myristoyl transferase. Cells were grown at $37{ }^{\circ} \mathrm{C}$ to an $\mathrm{OD}_{600}$ of approximately 0.5 in LB medium containing $100 \mu \mathrm{g} / \mathrm{mL}$ ampicillin, 12.5 $\mu \mathrm{g} / \mathrm{mL}$ chloramphenicol, and $30 \mu \mathrm{g} / \mathrm{mL}$ kanamycin, then supplemented with $50 \mu \mathrm{g} / \mathrm{mL}$ myristic acid. Thirty minutes after the addition of myristic acid, the expression of GCAP2 was induced by the addition of isopropyl-1-thio- $\beta$-D-galactosidase (IPTG) to a final concentration of $0.5 \mathrm{mM}$. Expression was allowed to proceed for $4 \mathrm{~h}$. Induced cells from $1 \mathrm{~L}$ of culture were collected by centrifugation, resuspended in $50 \mathrm{~mL}$ of $50 \mathrm{mM}$ Tris- $\mathrm{HCl}, \mathrm{pH} 8$, and stored frozen at -20 ${ }^{\circ} \mathrm{C}$ until further use. The thawed cell suspension was incubated at $30{ }^{\circ} \mathrm{C}$ for $30 \mathrm{~min}$ in the presence of $100 \mu \mathrm{g} / \mathrm{mL}$ lysozyme (SERVA) and 10 units/mL DNase1 (TaKaRa). Lysis was terminated by the addition of $1 \mathrm{mM}$ DTT $(1,4-$ ditiothreitol) and $0.1 \mathrm{mM}$ PMSF (phenylmethanesulfonyl fluoride). The insoluble fraction was collected by centrifugation at $370000 \mathrm{~g}$ for $20 \mathrm{~min}$ and solubilized by stirring in $250 \mathrm{~mL}$ of a buffer containing $6 \mathrm{M}$ guanidinium hydrochloride, $0.1 \mathrm{mM}$ PMSF, and $2.5 \mathrm{mM}$ DTT for $1 \mathrm{~h}$ at room temperature. The resulting suspension was filtered and dialyzed at $4{ }^{\circ} \mathrm{C}$ against three changes of $10 \mathrm{mM}$ sodium phosphate buffer, $\mathrm{pH} 7$, containing $1 \mathrm{mM}$ EDTA and $1 \mathrm{mM}$ DTT, followed by two changes of $10 \mathrm{mM}$ sodium phosphate buffer containing $200 \mu \mathrm{M} \mathrm{CaCl}_{2}$ and $1 \mathrm{mM}$ DTT. Precipitated material was removed by centrifugation at $370000 \mathrm{~g}$ for $20 \mathrm{~min}$. The supernatant was concentrated using Centriplus devices (Amicon) with a molecular cutoff of $10 \mathrm{kDa}$. The concentrate was then applied to a Superdex75 XK16/ 60 gel-filtration column (Pharmacia) in $10 \mathrm{mM}$ sodium

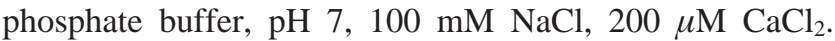
Fractions containing recombinant GCAP2 were pooled and bound to an UnoQ 6 column. Elution was performed by a gradient of $50-500 \mathrm{mM} \mathrm{NaCl}$ in $5 \mathrm{mM}$ sodium phosphate buffer, $\mathrm{pH} 7$, containing $20 \mu \mathrm{M} \mathrm{CaCl}_{2}$. Recombinant GCAP2 was obtained in $>95 \%$ purity, as determined by sodium dodecyl sulfate-polyacrylamide gel electrophoresis (SDSPAGE) followed by Coomassie staining.

Expression Studies. (i) COS Cells. COS-7 cells (simian virus 40-transformed African green monkey kidney cells), maintained in Dulbecco's modified Eagle's medium with penicillin/streptomycin and $10 \%$ fetal bovine serum, were transfected with the expression constructs FLAG-ROS-GC1 or FLAG-ERT $\rightarrow$ DCM by the calcium phosphate coprecipitation technique (42). Sixty hours after transfection, cells were washed twice with $50 \mathrm{mM}$ Tris- $\mathrm{HCl}(\mathrm{pH} 7.5) / 10 \mathrm{mM}$ $\mathrm{MgCl}_{2}$ buffer, scraped into $2 \mathrm{~mL}$ of ice-cold buffer, homogenized, centrifuged for $15 \mathrm{~min}$ at $5000 \mathrm{~g}$, and washed several times with the same buffer; the pellet represented the crude membranes. (ii) HEK293 Cells. HEK293 cells (human embryonic kidney cells) were grown in minimal essential medium (Eagle) with $2 \mathrm{mM}$ glutamine, $10 \%$ fetal calf serum, $1 \%$ nonessential amino acids, and 1\% antimycotic/antibiotic solution. They were transfected with the appropriate expression constructs and the plasmid pRSVTAG (43) by the calcium phosphate method (42). To enhance the expression of ROS-GC1 and its mutant, sodium butyrate $(0.5 \mathrm{M}$ in PBS) was added to a final concentration of 0.75 $\mathrm{mM}$ at $30 \mathrm{~h}$ posttransfection. $48 \mathrm{~h}$ posttransfection, the cells were harvested, washed with PBS, resuspended in $100 \mu \mathrm{L}$ of lysis buffer (10 mM HEPES-KOH pH 7.5, 1 mM DTT, $0.1 \mathrm{mM}$ PMSF), sonicated and centrifuged to remove cellular debris. The resulting supernatant was centrifuged at 4500 rpm for $15 \mathrm{~min}$. The pelleted membranes were resuspended in $50 \mu \mathrm{L}$ of lysis buffer (10 mM HEPES-KOH pH 7.5, 250 $\mathrm{mM} \mathrm{KCl}, 10 \mathrm{mM} \mathrm{NaCl}, 1 \mathrm{mM}$ DTT). Protein concentrations of the membrane suspensions were determined with the amido black method using bovine serum albumin as a standard (44).

Guanylate Cyclase Activity Assay. The crude membranes of COS cells were assayed for guanylate cyclase activity as described previously $(7,8)$. Briefly, the membranes were preincubated in an ice-bath with or without GCAP1, GCAP2, or $\mathrm{S} 100 \beta$ in the assay system containing $10 \mathrm{mM}$ theophylline, $15 \mathrm{mM}$ phosphocreatine, $20 \mu \mathrm{g}$ of creatine kinase, and 50 $\mathrm{mM}$ Tris- $\mathrm{HCl}(\mathrm{pH} 7.5)$ and adjusted to the appropriate free $\mathrm{Ca}^{2+}$ concentrations with precalibrated $\mathrm{Ca}^{2+} /$ EGTA solutions (Molecular Probes). Total assay volume was $25 \mu \mathrm{L}$. The reaction was initiated by the addition of the substrate solution containing $4 \mathrm{mM} \mathrm{MgCl}_{2}$ and $1 \mathrm{mM} \mathrm{GTP} \mathrm{(final} \mathrm{concentra-}$ tion). Incubation $\left(37^{\circ} \mathrm{C}, 10 \mathrm{~min}\right)$ was terminated by the addition of $225 \mu \mathrm{L}$ of $50 \mathrm{mM}$ sodium acetate buffer $(\mathrm{pH}$ 6.25) followed by heating in a boiling water bath for $3 \mathrm{~min}$. The amount of cyclic GMP formed was determined by radioimmunoassay (45).

HEK293 cell membranes were assayed for their guanylate cyclase activity in the presence of $100 \mu \mathrm{M}$ ATP and 400 $\mu \mathrm{M}$ Zaprinast as described previously (27). Basal activities were determined with manganese as cofactor.

Western Blot. After boiling in gel-loading buffer $[62.5 \mathrm{mM}$ Tris- $\mathrm{HCl}$ (pH 7.5), $2 \%$ SDS, $5 \%$ glycerol, $1 \mathrm{mM} \beta$-mercaptoethanol, and $0.005 \%$ bromophenol blue], $20 \mu \mathrm{g}$ of membrane protein was subjected to SDS-PAGE in a buffer ( $\mathrm{pH}$ 8.3) containing $0.025 \mathrm{M}$ Tris, $0.192 \mathrm{M}$ glycine, and 0.1\% SDS. The proteins were transferred to Immobilon membranes (Millipore) in the same buffer but containing 5\% methanol. The blot was incubated in Tris-buffered saline (TBS, $\mathrm{pH} 7.5$ ) containing $100 \mathrm{mM}$ Tris- $\mathrm{HCl}, 0.9 \% \mathrm{NaCl}$, and $0.05 \%$ Tween20 (TBS-T) with $5 \%$ powdered nonfat Carnation milk (blocking buffer) overnight at $4{ }^{\circ} \mathrm{C}$ and rinsed with TBS-T. The anti-FLAG monoclonal antibodies (Sigma) were added at 1:300 dilution in the blocking buffer and the incubation was continued for $1 \mathrm{~h}$. After the blot was rinsed with TBS$\mathrm{T}$, the incubation was continued with the secondary antibody conjugated to horseradish peroxidase in blocking buffer (1: 20000) for another hour. Finally the blot was treated with SuperSignal blaze chemiluminescent substrate (Pierce) for 5 min according to the manufacturer's protocol. The immunoreactive band was detected by exposing the blot to Kodak $\mathrm{X}$-ray film for $15 \mathrm{~s}$.

Cross-Linking. Cross-linking was performed using homobifunctional $N$-hydroxy-succinimide (NHS) ester harboring a spacer with length of $11.4 \AA$, the water-soluble bis(sulfosuccinimidyl)suberate (BS ${ }^{3}$, Pierce). The cross-linker was added to a ROS suspension (1 mg of rhodopsin) at a final concentration of $1 \mathrm{mM}$. The reaction mixture $(0.1 \mathrm{~mL})$ was incubated for $20 \mathrm{~min}$ at room temperature and the reaction was stopped by the addition of $50 \mathrm{mM}$ Tris- $\mathrm{HCl}$, $\mathrm{pH}$ 8.0. For cross-linking of the heterologously expressed ROS-GC1 and its mutant, HEK293 membranes were diluted by half with a solution containing $2 \mathrm{mM} \mathrm{BS}^{3}$. The reaction mix was incubated for $15 \mathrm{~min}$ at room temperature. The 


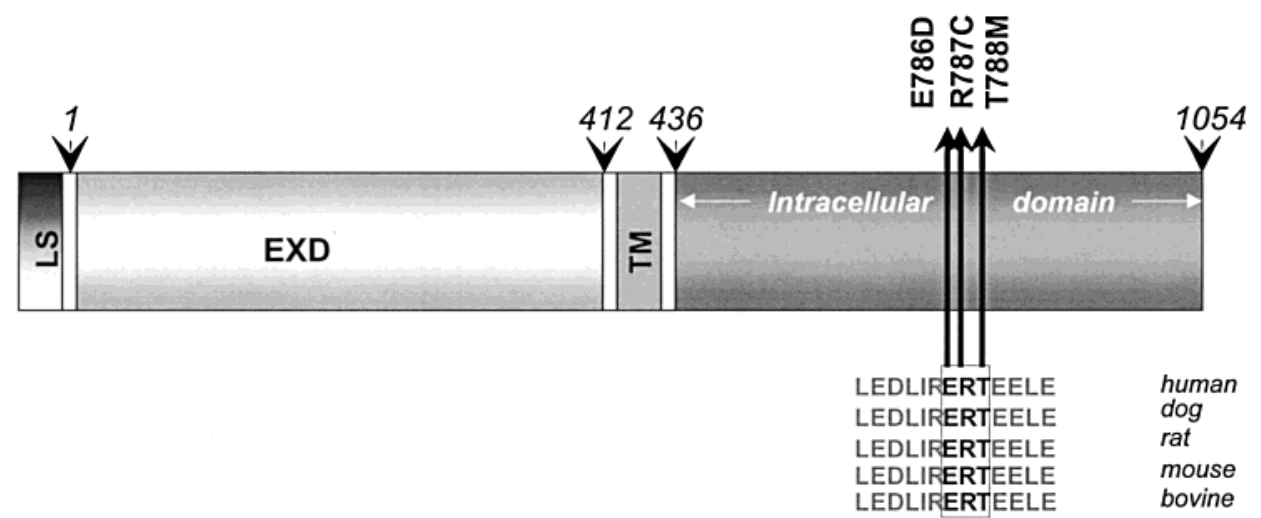

FIGURE 1: Schematic representation of the ROS-GC1 protein. The following denote the predicted domains: LS, leader sequence; EXT, extracellular (intradiscal) domain; TM, transmembrane domain; DD, dimerization domain. Numbers indicated correspond to the mature protein (11). Alignment of the human, dog, rat, mouse, and bovine amino acid sequences (GenBank accession numbers M92432/AJ222675, Y15483, Y15483, L36029, L41933, L37089, respectively) in the region surrounding positions 786, 787, and 788 is shown.

influence of $\mathrm{Ca}^{2+}$-binding proteins on the cross-linking efficiency was assayed at a final concentration of $10 \mu \mathrm{M}$ of GCAP-1, GCAP-2, or S100 $\beta$, respectively. Samples with $\mathrm{Ca}^{2+}$-binding proteins were incubated in the presence of 2 mM EGTA or $2 \mathrm{mM} \mathrm{CaCl}_{2}$. The cross-linking reaction was stopped by the addition of three volumes of SDS-PAGE sample buffer. Samples were analyzed for cross-linked products by SDS-PAGE and Western blotting using a polyclonal anti ROS-GC1 antibody (1:5000) and HRPcoupled secondary antibody (anti rabbit $\mathrm{IgG}$ ) (46). Bands were detected by enhanced chemiluminescence (ECL). For quantitation of bands, the chemiluminescence was recorded with an Image Station 440 CF (Kodak). The resulting images were digitally stored and evaluated using Kodak Digital Science 1-D software (version 3.02).

Gel-Filtration Chromatography. (1) Expression and Purification of the aa 733-1054 Fragment of wt-rROS-GC1 and of the ERT $\rightarrow D C M$ Mutant. A 966 bp fragment corresponding to aa 733-1054 of wt-rROS-GC1 (10) and of the ERT $\rightarrow$ DCM mutant was amplified by PCR and cloned in frame into pET30a bacterial expression vector (Novagen) between EcoRV and XhoI sites. The construct was verified by sequencing and transformed into E. coli ER2566 for expression. Initially, clones were screened for inducible expression of the ROS-GC1 fragment. For a large scale culture, overnight grown cells $(1 \%)$ were inoculated into LB containing $100 \mu \mathrm{g} / \mathrm{mL}$ kanamycin and grown to an OD of 0.6 at $600 \mathrm{~nm}$. At this stage, expression of the fragment was induced by the addition of IPTG ( $1 \mathrm{mM}$ final concentration). The cells were harvested 3-4 $\mathrm{h}$ after induction and resuspended in $0.04 \mathrm{vol}$ of buffer containing $20 \mathrm{mM}$ Tris- $\mathrm{Cl}$ and $300 \mathrm{mM} \mathrm{NaCl}$. This suspension was sonicated (8 pulses of $20 \mathrm{~s}$ each) to break open the cells. This was followed by centrifugation at $13000 \mathrm{~g}$ to pellet the inclusion bodies, which contained the expressed protein. The inclusion bodies were resuspended in buffer containing $100 \mathrm{mM}$ sodium phosphate, $10 \mathrm{mM}$ Tris-Cl, $2 \mathrm{mM}$ DTT, and $8 \mathrm{M}$ urea (pH 8.0) and incubated for $60 \mathrm{~min}$ at room temperature with shaking to extract the proteins into the buffer. After $60 \mathrm{~min}$, the debris was pelletted by centrifugation. The supernatant was incubated with 0.25 volumes of Ni-NTA resin (Qiagen) (preequilibrated in the same buffer) at room temperature on a rotary shaker for $2-5 \mathrm{~h}$. This suspension was loaded on a column, where the His-tagged protein was retained with the
Ni-NTA resin. The column was washed with 20 vol of buffer containing $100 \mathrm{mM}$ sodium phosphate, $10 \mathrm{mM}$ Tris- $\mathrm{Cl}$, and $8 \mathrm{M}$ urea (pH 6.3) followed by $4 \mathrm{vol}$ of the same buffer at $\mathrm{pH}$ 5.9. The expressed protein was eluted with $4 \mathrm{vol}$ of the same buffer at $\mathrm{pH} 4.5$. Refolding of the eluted protein was carried out according to ref 48 . After dialysis, the protein solution was concentrated using centricon-30 filters (Millipore). The protein thus obtained was of $>95 \%$ purity as determined by SDS-PAGE. (2) Gel-Filtration. This was carried out on a Superdex-75 column using an LCC-501 controller managed by fast-protein liquid chromatography (FPLC) director on an FPLC system (Pharmacia Biotech). The sample was loaded using a $100 \mu \mathrm{L}$ loop and eluted with a buffer containing $20 \mathrm{mM}$ Tris- $\mathrm{Cl}$ and $150 \mathrm{mM} \mathrm{NaCl}(\mathrm{pH}$ 7.4). The flow rate was maintained at $0.5 \mathrm{~mL} / \mathrm{min}$. and 0.5 $\mathrm{mL}$ fractions were collected. The elution was monitored by measuring absorbance at $280 \mathrm{~nm}$. The major peak was that of guanylate cyclase. This peak fraction was independently identified based on enzyme activity. Quantitation of the peak was carried out through integration of the area under the peak after subtraction of the baseline.

\section{RESULTS}

$E R T \rightarrow D C M$ Mutation in ROS-GC1 Damages the Basal Cyclase State. CORD6 is heterogeneous. Previous studies have linked two missense point mutations in the ROS-GC1 gene, resulting in the amino acid substitutions E786D and R787C, with this disease in four British families (38). Each inflicted family contains only one of the above mutations. Biochemically, these mutations produce varying effects on the basal cyclase activity, and they have been discussed in detail in previous studies $(8,9)$. The triple mutation linked with another case of CORD6 involves amino acids: E786, R787, and T788 (37). This indicates that all CORD6 cases reported so far cover amino acids at adjacent positions in ROS-GC1, hence, this region of the cyclase is mutationprone. Alignment of a 13 amino acid domain surrounding the E786, R787, and T788 residues shows complete identity between its human, dog, rat, mouse, and bovine forms (Figure 1). Thus, the region is totally conserved in ROSGC1.

To elucidate how the ERT $\rightarrow$ DCM substitutions affect the biochemical features of ROS-GC1, these mutations were 

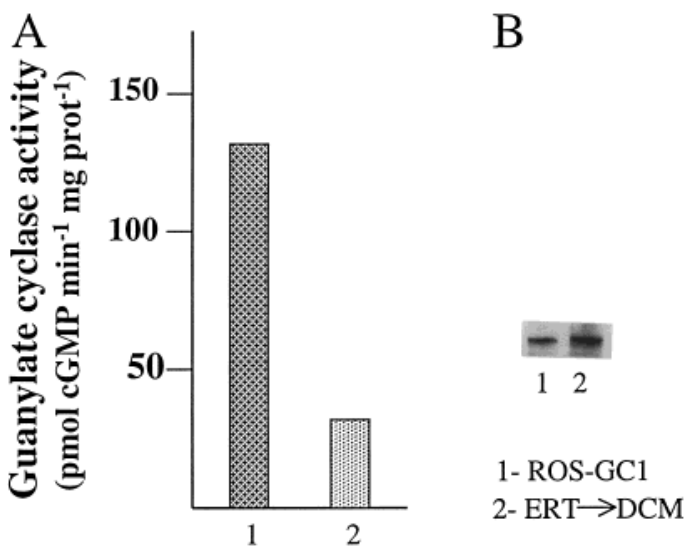

Figure 2: Expression of the wt-rROS-GC1 and of the triple substitution ERT $\rightarrow$ DCM mutant proteins. (A) Guanylate cyclase activity. COS7 cells were individually transfected with the appropriate expression constructs, and the membranes were prepared as described under Materials and Methods. These were assayed for guanylate cyclase activity. The experiment was repeated three times for reproducibility. (B) Western blot. Proteins ( $20 \mu \mathrm{g}$ of COS7 cell membranes containing FLAG-ROS-GC1 of FLAG-ERT $\rightarrow$ DCM) were subjected to SDS-PAGE. After electrophoresis the proteins were transferred to Immobilon membranes, and the blots were incubated with anti-FLAG monoclonal antibody and with the secondary antibody as described under Materials and Methods. Immunoreactive bands were visualized by exposing the blots to Kodak X-ray film. The experiment was repeated three times with membranes prepared from separate transfection experiments.

introduced into wild-type recombinant (wt-r) ROS-GC1. The cyclase was expressed in COS cells which under native conditions do not express ROS-GC1. ROS-GC1 leader sequence was retained in the expression construct to ensure proper translocation and folding of the protein. The cell membranes expressing the wt-rROS-GC1 or the mutant were tested for basal cyclase activity. In parallel, the expression level of the protein was assessed. A highly immunogenic FLAG (DYKDDDDK) epitope was inserted into the cyclases immediately after the signal peptide cleavage site $(3,10)$. Insertion of FLAG sequence does not alter the basal cyclase activity $(7,8)$. COS cell membranes expressing the FLAGcontaining constructs were subjected to Western analysis with anti-FLAG monoclonal antibodies. The blots showed single immunoreactive bands of almost equal intensity (Figure 2B), indicating comparable expression of the proteins.

The basal activity of the wt-rROS-GC1 was $130 \pm 10$ pmol of cyclic GMP $\min ^{-1}$ (mg of protein $)^{-1}$. In contrast the activity of the ERT $\rightarrow$ DCM mutant was $30 \pm 5$ pmol of cyclic GMP $\min ^{-1}$ (mg of protein) $)^{-1}$ (Figure 2A). This indicates that the mutation severely damages the basal state of the enzyme.

$E R T \rightarrow D C M$ Mutation Increases the Activity of Phototransduction-Linked Modules of ROS-GCl. There are presumably two phototransduction-linked modules in ROS-GC1. GCAP1 modulates one and GCAP2, the other. These are distinct modules, which do not overlap with each other $(8$, $22)$. The current phototransduction model predicts that GCAPs are bound to the cyclase in its native state $(16,27)$. They are under tight control of the intracellular levels of $\mathrm{Ca}^{2+}$. Increments in $\mathrm{Ca}^{2+}$ are sensed by the GCAPs and cause progressive decrease in the activity of ROS-GC1. To determine whether the ERT $\rightarrow$ DCM mutation has any effect on the cyclase response to these modulators, COS cell
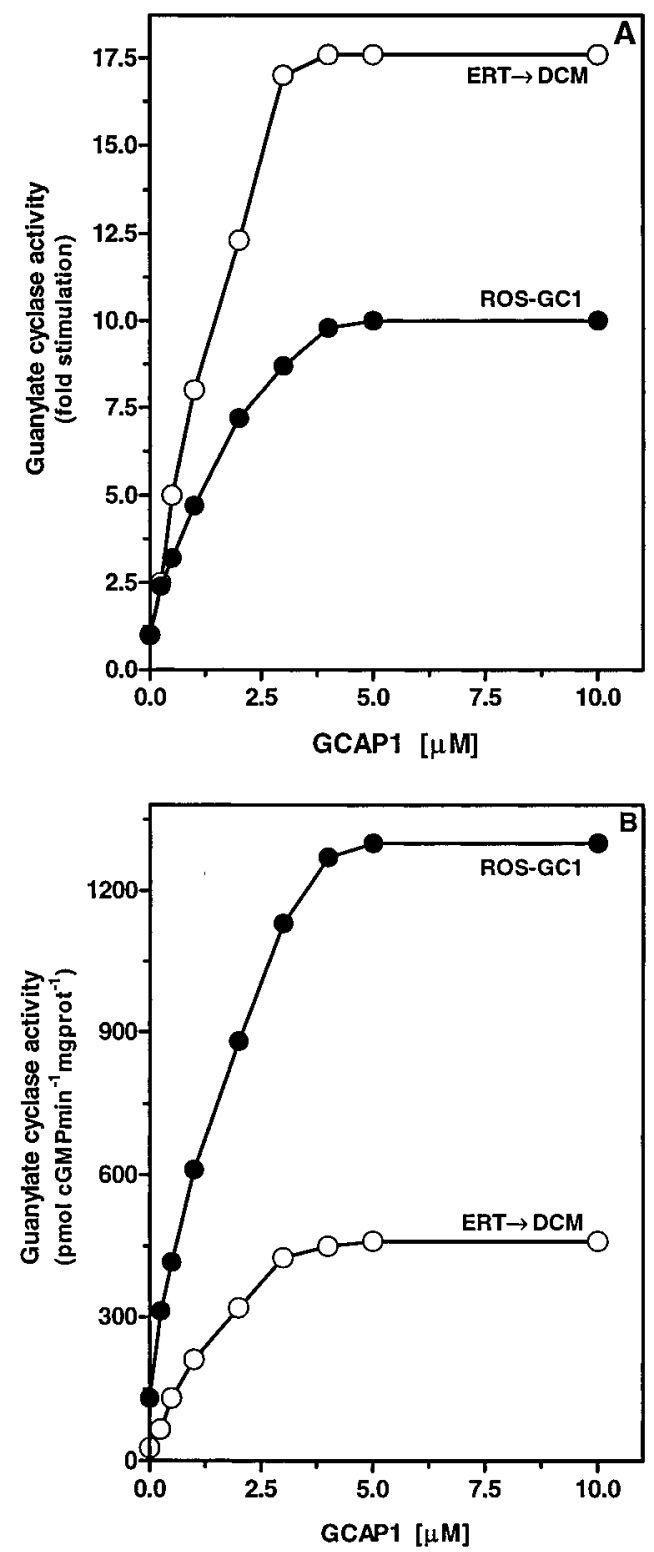

FIGURE 3: Effect of GCAP1 on the cyclase activity of the wtrROS-GC1 and ERTfDCM mutant proteins. COS7 cells were transfected with appropriate expression constructs and the membranes were prepared as described under Materials and Methods. These were assayed for guanylate cyclase activity in the presence of $10 \mathrm{nM} \mathrm{Ca}{ }^{2+}$ and incremental concentrations of GCAP1. The guanylate cyclase activity was calculated as fold stimulation above the basal value (A) or as the cyclase specific activity (B). Each experiment was done in triplicate and repeated at least three times with separate membrane preparations. The depicted curves are from one representative experiment. Error bars are within the size of the symbols.

membranes expressing the wt-rROS-GC1 or the mutant protein were exposed to increasing concentrations of GCAP1 or GCAP2 at a $\mathrm{Ca}^{2+}$ concentration of $10 \mathrm{nM}$. GCAP1 stimulated both cyclases in a dose-dependent fashion with $\mathrm{EC}_{50}$ of $\sim 1 \mu \mathrm{M}$ and saturation at $\sim 3 \mu \mathrm{M}$. There was a significant difference in the maximal activation achieved by the cyclases. The wt-rROS-GC1 was stimulated approximately 10 -fold over the basal value, but the ERT $\rightarrow$ DCM mutant, almost 18-fold (Figure 3A). However, this increased responsiveness of the ERT $\rightarrow$ DCM mutant to GCAP1 was not enough to compensate for the loss in the mutant's basal activity. The amount of cyclic GMP formed at any GCAP1 

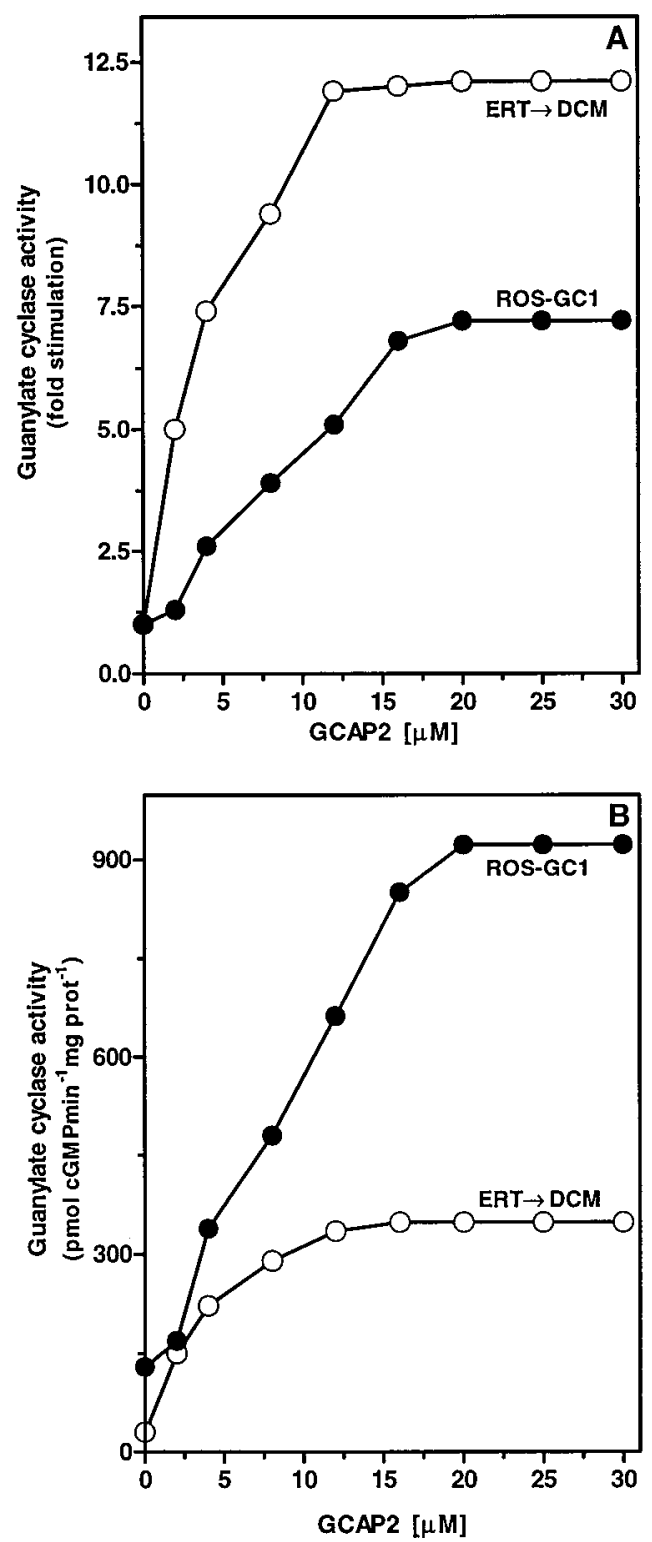

FIGURE 4: Effect of GCAP2 on the cyclase activity of the wtrROS-GC1 and ERT $\rightarrow$ DCM mutant proteins. The experimental conditions were as described for GCAP1, except that GCAP2 was used. The guanylate cyclase activity was calculated as fold stimulation above the basal value (A) or as the cyclase specific activity (B). Each experiment was done in triplicate and repeated at least three times with separate membrane preparations. The depicted curves are from one representative experiment. Error bars are within the size of the symbols.

concentration was no more than $35 \%$ of the amount formed under the same conditions by wt-rROS-GC1 (Figure 3B). Thus, the mutation leads to a state where the cyclase becomes overresponsive to GCAP1 stimulation, but the net formation of cyclic GMP is impaired due to lowered basal activity.

When the effect of GCAP2 was tested, the ERT $\rightarrow$ DCM mutant responded again with an increased stimulation in comparison with wt cyclase. The maximal stimulation was 12.5-fold over the basal value for the mutant, whereas the wt-rROS-GC1 was stimulated 7.5-fold (Figure 4A). There was small, albeit noticeable, difference in the respective $\mathrm{EC}_{50}$ values for GCAP2: the $\mathrm{EC}_{50}$ value in case of the mutant was $4 \mu \mathrm{M}$ while it was $8 \mu \mathrm{M}$ in case of the wt-rROS-GC1 (Figure 4A). Thus, the mutation results in a small increase in the cyclase affinity for GCAP2. However, despite the increased responsiveness and affinity toward GCAP2, the $\mathrm{ERT} \rightarrow \mathrm{DCM}$ mutant is able to synthesize only about onethird of the cyclic GMP compared to the wt cyclase (Figure 4B).

To determine whether the ERT $\rightarrow$ DCM mutation alters the $\mathrm{Ca}^{2+}$ sensitivity of GCAP1- or GCAP2-dependent stimulation of the cyclase, the $\mathrm{Ca}^{2+}$-dependent modulation of the cyclase was tested at varying concentrations of $\mathrm{Ca}^{2+}$ and constant concentrations of GCAP1 or GCAP2 (Figure 5, panels A and B). The pattern was identical for the wt and mutant ROSGC1. The cyclase activity decreased when the free $\mathrm{Ca}^{2+}$ increased. Half-maximal inhibition $\left(\mathrm{IC}_{50}\right)$ was at about 110 $\mathrm{nM}$ free $\mathrm{Ca}^{2+}$. Thus, the ERT $\rightarrow$ DCM mutation does not affect the calcium sensitivity of the cyclase. It, however, diminishes the responsiveness of the cyclase to GCAPs. In the final analysis, the mutation has altered the phototransduction-linked modules of the cyclase without altering their calcium sensitivity.

$E R T \rightarrow D C M$ Mutation Drastically Reduces the Activity of the Synapse-Linked Module of ROS-GC1. In addition to being linked with phototransduction, ROS-GC1 is also linked with the retinal synapse activity. The linkage occurs via a module, which is distinct from those linked with phototransduction $(23,28)$. Here $\mathrm{Ca}^{2+}$ through $\mathrm{S} 100 \beta$ stimulates the module. To determine whether the ERT $\rightarrow$ DCM substitution has any effect on the synapse-linked module, the membranes expressing the mutant were assayed for the cyclase activity in the presence of increasing concentrations of $\mathrm{S} 100 \beta$, at $1 \mathrm{mM}$ $\mathrm{Ca}^{2+}$. Control experiments were carried out with wt-rROSGC1. Although the mutant was stimulated in a dosedependent fashion, the maximal stimulation achieved was three times lower than that of wt-rROS-GC1: $\sim 5$-fold stimulation was observed for the mutant whereas wt-rROSGC1 was stimulated $\sim 15$-fold (Figure $6 \mathrm{~A}$ ). When the amounts of cyclic GMP formed by the mutated and wtcyclases were compared, the difference was even more striking. At the maximal concentration of $\mathrm{S} 100 \beta$, the amount of cyclic GMP formed by the mutated cyclase was only $5-8 \%$ of the amount formed by wt-rROS-GC1 (Figure 6B), although no change in sensitivity to $\mathrm{Ca}^{2+}$ was observed (Figure 5C). This indicates that this module is almost completely nonfunctional in the mutant. Thus, the mutation has incapacitated the retinal synapse-linked module.

HEK293 and COS Cells Expression Systems Are Comparable. It was noticed that the use of COS or HEK293 cells for the expression of ROS-GC1 or its mutants occasionally leads to different results (27). Therefore, the consequences of the ERT $\rightarrow$ DCM substitution in ROS-GC1 were tested using the HEK293 system in addition to the COS cell expression system. Qualitatively, the results obtained with both systems were similar. The basal activity decreased to about $15 \pm 9 \%$ of the value measured with the wt-rROSGC1. The mutant was also over-responsive to GCAP1 but less responsive to GCAP2 and lost nearly all responsiveness to $\mathrm{S} 100 \beta$ up to a concentration of $5 \mu \mathrm{M}$ (Figure 7). At maximal $\mathrm{S} 100 \beta$ concentration $(10 \mu \mathrm{M})$, the ERT $\rightarrow \mathrm{DCM}$ mutant retained only $7 \%$ of the activity measured with the wt-rROS-GC1. Some difference was observed in the doseresponse patterns. Higher concentrations were needed to reach half-maximal activation of the wt and the ERT $\rightarrow$ DCM mutant with GCAP1 and $\mathrm{S} 100 \beta$, but not GCAP2. Thus, it is 

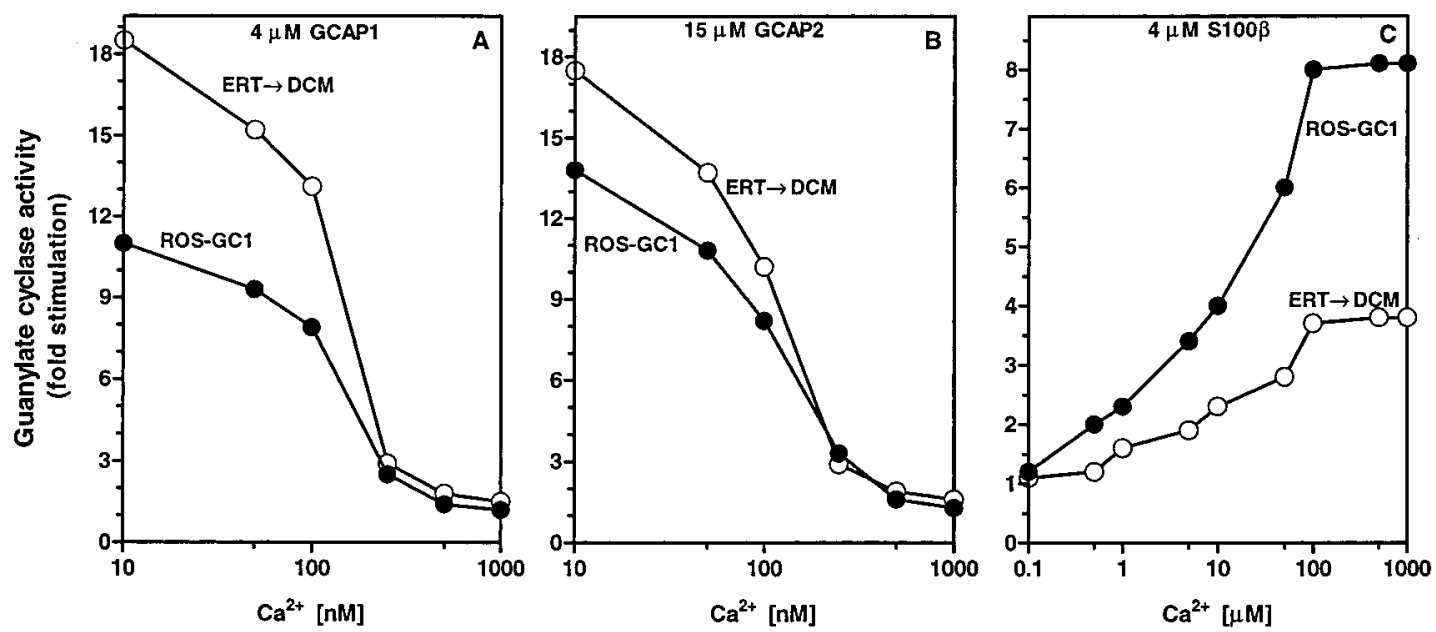

FIGURE 5: $\mathrm{Ca}^{2+}$ dependence of wt-rROS-GC1 and ERT $\rightarrow$ DCM mutant guanylate cyclase activities in the presence of $4 \mu \mathrm{M}$ GCAP1 (A), $15 \mu \mathrm{M}$ GCAP2 (B), or $4 \mu \mathrm{M} \mathrm{S100} \beta$ (C). Membranes of COS7 cells expressing wt-rROS-GC1 or the ERT $\rightarrow$ DCM mutant were assayed for guanylate cyclase activity in the presence of saturating concentrations of GCAP1, GCAP2, or S100 $\beta$ and increasing concentrations of free $\mathrm{Ca}^{2+}$. Each experiment was done in triplicate and repeated two times. The results presented are from one representative experiment. Error bars are within the sizes of the symbols.

concluded that the effect of the ERT $\rightarrow$ DCM mutation is similar in both the systems tested, although some important quantitative variations are observed. Significantly, in HEK293 cells, GCAP1 and GCAP2 are almost equipotent in stimulating ROS-GC1.

ERT $\rightarrow$ DCM Substitution Affects ROS-GCl Dimerization. Analyses of the results presented above indicate that under all tested experimental conditions, the amount of cyclic GMP formed by the ERT $\rightarrow$ DCM mutant is lower than that formed by wt-rROS-GC1. Earlier studies have indicated that the active state of ROS-GC1 is represented by its dimeric form $(29,30)$. To determine if the impaired functioning of the cyclase is a result of disturbed dimer formation, the dimerization of the wt and mutated ROS-GC1 was tested by crosslinking and gel-filtration chromatography.

(i) Cross-Linking. When native ROS-GC1 in a suspension of bovine ROS was incubated with the cross-linker $\mathrm{BS}^{3}$, two main bands, in addition to the ROS-GC1 monomer at 112 $\mathrm{kDa}$, were detected by the anti-ROS-GC1 antibody (Figure $8 \mathrm{~A}$, left panel). The band at $220 \mathrm{kDa}$ represented a ROS$\mathrm{GC} 1$ dimer; the band at the top gel was an oligomeric form of ROS-GC1 with an apparent molecular mass of more than $400 \mathrm{kDa}$.

A similar cross-linking pattern was observed when wtrROS-GC1 was heterologously expressed in HEK293 cells and subsequently cross-linked with $\mathrm{BS}^{3}$ (Figure 8A, middle panel). This indicated that native and heterologously expressed ROS-GC1 could be directly compared with respect to its monomeric, dimeric, and oligomeric forms. A significant change in the formation of a dimer was observed with the ERT $\rightarrow$ DCM mutant. The proportion of the different forms was quantitatively analyzed based on the band intensities. The results indicate that the ability of the ERT $\rightarrow$ DCM mutant to form a dimer decreased by $60-70 \%$ in comparison with the wt-rROS-GC1 (Figure 8A, right panel). The decrease was accompanied by a corresponding decrease in the cyclase activity (Figure 8C). Cross-linking was not influenced by the addition of $\mathrm{Ca}^{2+}$-binding proteins, GCAP1, GCAP2 and S100 $\beta$, at $2 \mathrm{mM}$ EGTA or $1 \mathrm{mM} \mathrm{CaCl} 2$ (data not shown). Thus, the ERT $\rightarrow$ DCM mutation disturbs the dimerization of ROS-GC1 and thereby causes impairment in the synthesis of cyclic GMP.

(ii) Gel-Filtration Chromatography. The fragments corresponding to aa 733-1054 of ROS-GC1 and of the ERT $\rightarrow$ DCM mutant were expressed in bacterial cells and purified to homogeneity. The expressed fragment encompassed the putative dimerization and catalytic domains of the cyclase. Can the expressed proteins serve as a proper model for studies on the dimerization of ROS-GC1? To test the integrity of both fragments, their cyclase catalytic activities and their abilities to respond to GCAP1, GCAP2, or $\mathrm{S} 100 \beta$ at the appropriate free $\mathrm{Ca}^{2+}$ concentrations were tested.

Both proteins exhibited cyclase activities (Figure 9). They were $6 \pm 0.5$ and $1.5 \pm 0.25 \mathrm{pmol}$ of cyclic GMP $\min ^{-1}$ (mg of protein $)^{-1}$, respectively, for the ROS-GC1 and for the mutant fragments. These activities were considerably lower than the activities of the full length proteins. Similar lowering of the basal activity has been observed earlier for the expressed soluble fragments of the human analogue of ROS-GC1 (47) and for the atrial natriuretic factor receptor guanylate cyclase (ANF-RGC) (48, 49). Significantly, however, the activity of the mutant-derived fragment was $\sim 4$-fold lower than that of the wt-rROS-GC1-derived fragment indicating that the mutations affected the soluble fragment in a fashion similar to the full-length protein.

When exposed to $5 \mu \mathrm{M}$ GCAP1 or $20 \mu \mathrm{M}$ GCAP2 at 10 $\mathrm{nM} \mathrm{Ca}{ }^{2+}$, both fragments responded to GCAP2 with $\sim 3-$ fold increased cyclic GMP formation. They, however, failed to respond to GCAP1 (Figure 9). These results are consistent with the previous conclusions that GCAP1- and GCAP2responsive ROS-GC1 modules are distinct and their domains do not overlap (22). The lack of response with GCAP1 is also consistent with a recent study (27), which shows that GCAP1 sensitive module in ROS-GC1 is located in the juxtamembrane domain. This module is missing in the soluble fragment. However, soluble fragments derived from both the ERT $\rightarrow$ DCM and the wt-cyclase, were stimulated by $\mathrm{S} 100 \beta$ at $1 \mathrm{mM} \mathrm{Ca}{ }^{2+}$ (Figure 9). These results demonstrate that the soluble fragments retain the native biochemical 

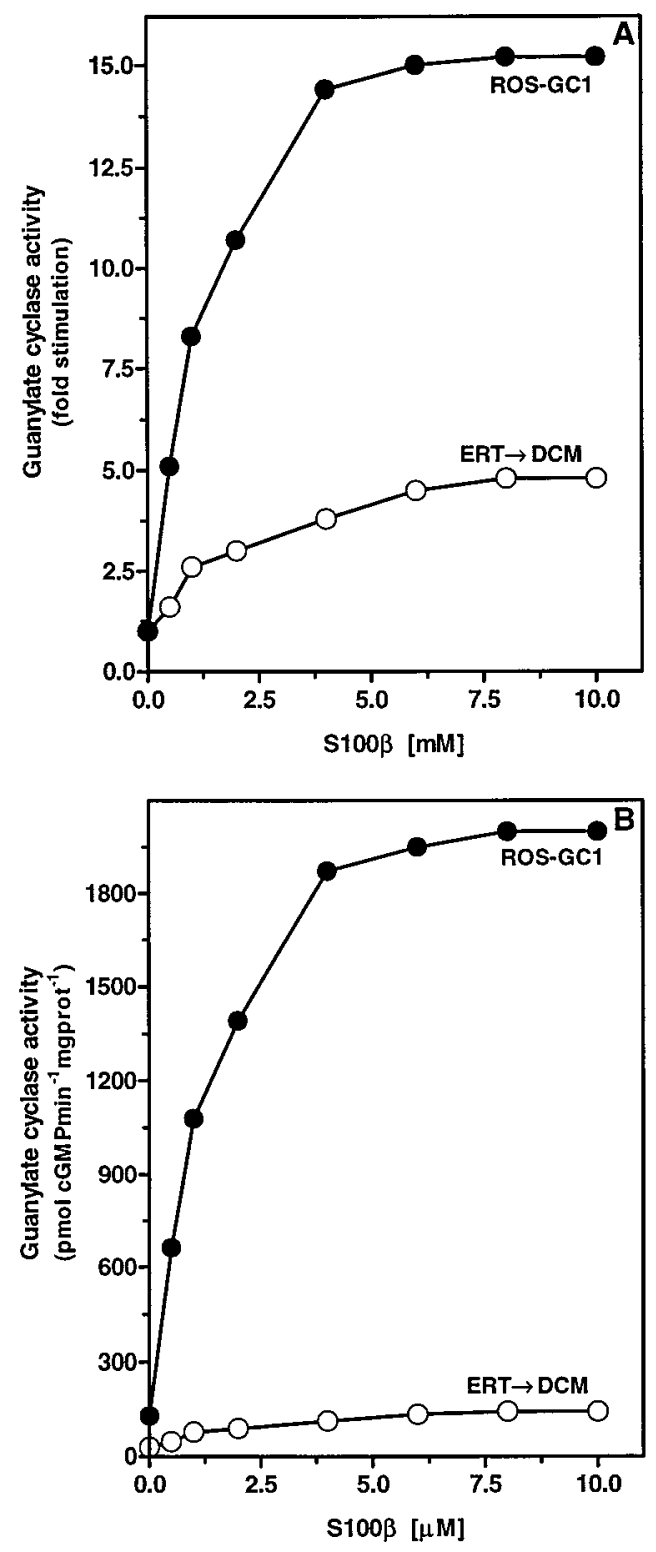

FIGURE 6: Effect of $\mathrm{S} 100 \beta$ on the cyclase activity of the wt-rROSGC1 and ERT $\rightarrow$ DCM mutant proteins. COS7 cells were transfected with appropriate expression constructs and the membranes were prepared as described under Materials and Methods. These were assayed for guanylate cyclase activity in the presence of $1 \mathrm{mM}$ $\mathrm{Ca}^{2+}$ and incremental concentrations of $\mathrm{S} 100 \beta$. The guanylate cyclase activity was calculated as fold stimulation above the basal value (A) or as the cyclase specific activity (B). Each experiment was done in triplicate and repeated at least three times with separate membrane preparations. The depicted curves are from one representative experiment. Error bars are within the size of the symbols.

features of ROS-GC1, are sensitive to the mutations in question, and are therefore suitable tools for the dimerization studies.

The monomer/dimer statuses of the wt and of the mutant soluble fragments were determined through the gel-filtration chromatography. The proteins were individually analyzed on a Superdex-75 column precalibrated for molecular size in an FPLC system. Their elutions were monitored by measuring absorbancies at $280 \mathrm{~nm}$ and the guanylate cyclase activity was determined in all eluted fractions. The fragment originating from wt-rROS-GC1 was eluted in two fractions. The first fraction accounted for $75 \%$ of the protein and its molecular weight corresponded to that of a dimer; the remaining $25 \%$ were eluted as a monomer (Figure 10). The fragment derived from the ERT $\rightarrow$ DCM mutant eluted as a single peak at a position corresponding to a monomer (Figure 10). These results are consistent with the cross-linking experiments carried out on the intact ROS-GC1. They show that the ERT $\rightarrow$ DCM mutation within the predicted dimerization domain effectively disturbs the dimer formation. There is, however, a noticeable difference between results of cross-linking and gel-filtration experiments, which may be a result of different types of proteins used for analysis. In the cross-linking studies, the full-length protein was used, and in the gel-filtration experiments a soluble fragment of ROS-GC1 was used. The intact protein shows some residual ability of the mutant to dimerize, whereas the isolated soluble fragment exhibits a complete disruption of dimerization in the mutant. This may be due to (1) stabilization of a weak ability to dimerize by the presence of a cross-linker; and/or (2) interactions favoring dimerization occurring in the cyclase regions outside the expressed portion. Despite these quantitative differences, the findings in both systems indicate an important role of dimerization in the active state of the cyclase. They further show that the ERT $\rightarrow$ DCM mutation interferes with the dimeric state of the cyclase.

\section{DISCUSSION}

This study defines a form of CORD6 resulting from the ERT $\rightarrow$ DCM mutation, in biochemical, molecular, and functional terms. At a most basic level, it supports the previously proposed concept that dimerization is an important mechanistic step in the activation of ROS-GC1. Furthermore, this study identifies the residues E786, R787 and T788 to be critical for dimerization of ROS-GC1; the ERT $\rightarrow$ DCM mutation impairs the process of dimerization. Thus, in ERT $\rightarrow$ DCM the enzyme is unable to fold properly and exhibit its optimum catalytic activity. The effects of this mutation on the basal and modulated states of ROS-GC1 are individually analyzed and their significance is discussed under "Biochemistry" and "Physiology". The implications of these findings in deriving a mechanistic theme are discussed separately. The final statements on the findings are put together in the "Conclusion".

Basal State. (i) Biochemistry. In its basal state, ROS-GC1 controls the dark current in the outer segments of rods and cones. In this state $\sim 5 \%$ of the cyclic GMP-gated channels are open $(1,50)$. The ERT $\rightarrow$ DCM mutation reduces the ROS-GC1 activity by about 5-fold. This will result in the closure of almost all of the channels.

(ii) Physiology. The closure of the channels will result in a lowered steady-state level of cyclic GMP in dark-adapted photoreceptor cell. Concomitant with the reduction of dark current, there will be a drop in cytoplasmic $\mathrm{Ca}^{2+}$ concentration because of the continued operation of the exchanger (51). This will result in a false light-adapted state of photoreceptors; The photoreceptor will perceive illumination without being in a state of illumination. Another consequence of the drop in $\mathrm{Ca}^{2+}$ levels will be that it initiates the $\mathrm{Ca}^{2+}$-dependent feedback signals by the $\mathrm{Ca}^{2+}$ sensors, GCAP1 and GCAP2. Thus, a shift in the response-light curve to the lower light intensities will occur. The photoreceptors of the afflicted individual will adapt at lower light intensities for a given 

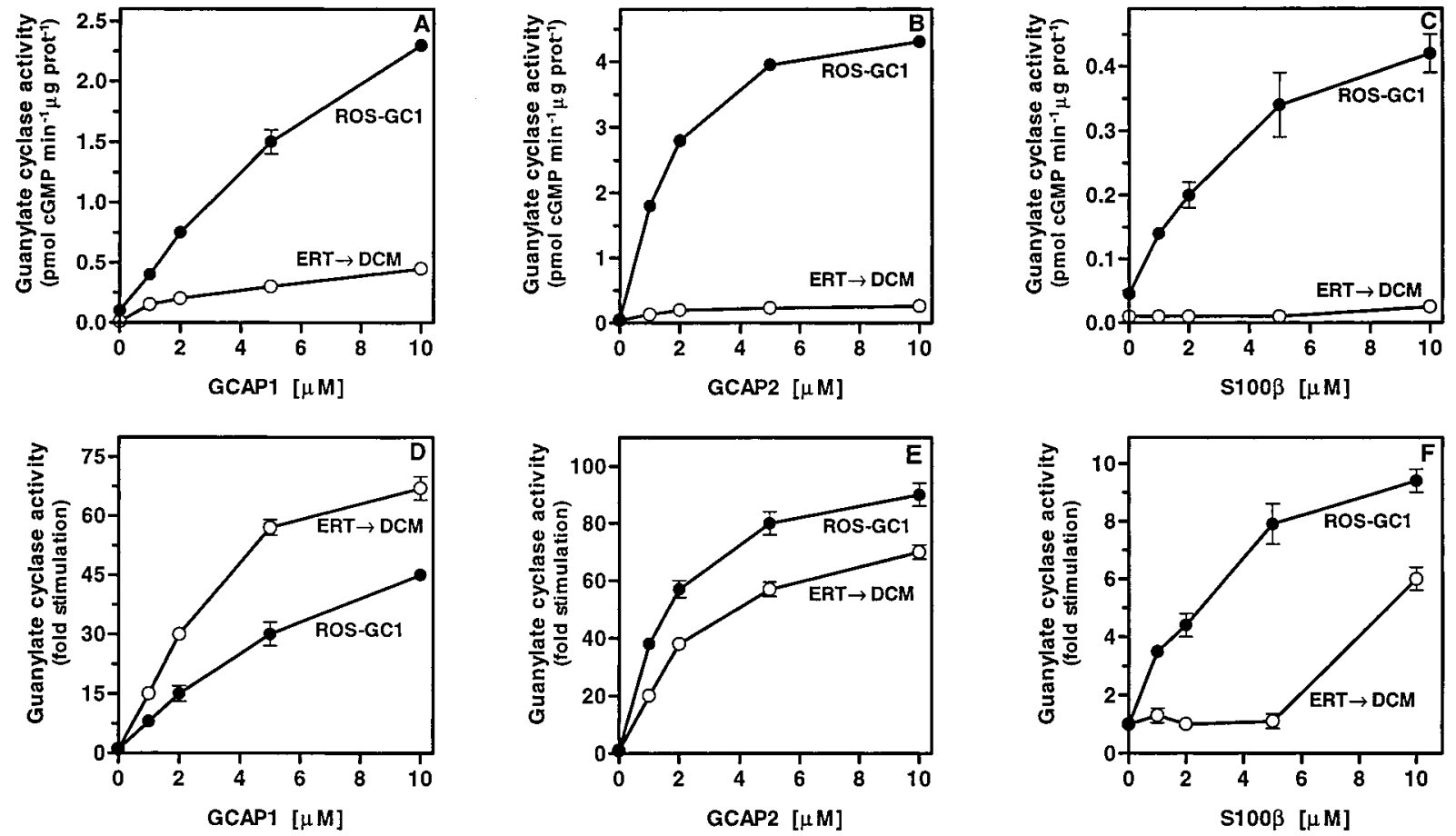

FIGURE 7: Effect of GCAP1 (A, D), GCAP2 (B, E), and S100 $\beta$ (C, F) on the cyclase activity of wt-rROS-GC1 and ERT $\rightarrow$ DCM mutant proteins expressed in HEK293 cells. Transient expression of wt-rROS-GC1 and of the ERT $\rightarrow$ DCM mutant in HEK293 cells and the membranes preparation were performed as described in Materials and Methods. The effect of GCAP1 and GCAP2 was analyzed in the presence of 2 $\mathrm{mM}$ EGTA and the effect of $\mathrm{S} 100 \beta$, in the presence of $2 \mathrm{mM} \mathrm{CaCl}_{2}$. The experiment was done in duplicate and repeated with separate membrane preparation. Results (mean \pm SD) are expressed as specific cyclase activities $(\mathrm{A}, \mathrm{B}, \mathrm{C})$ and fold stimulation over the activity without the activator proteins $(\mathrm{D}, \mathrm{E}, \mathrm{F})$.

background light. This prediction is borne out in the actual case of CORD6 (38).

Phototransduction-Linked Modules. (i) Biochemistry. The primary phototransduction-linked module in ROS-GC1 is regulated by $\operatorname{GCAP} 1(22,27)$. The ERT $\rightarrow$ DCM mutation alters the activity of this module. As a consequence, the maximal stimulation of the cyclase is 2-fold more than the wt-rROS-GC1. However, due to the 5-fold lower basal activity, the net cyclic GMP synthesized by the mutant is only about $35 \%$ when compared to the wild-type.

A similar situation exists with the GCAP2-regulated module in the ERT $\rightarrow$ DCM mutant. In the wt-rROS-GC1, this is a secondary phototransduction-linked module. This module is about 1 order of magnitude less selective in stimulating the cyclase (22). The ERT $\rightarrow$ DCM mutation increases the module activity: stimulation of the cyclase through this module increases about $50 \%$ over the wt-rROSGC1. Again due to the lowered basal activity, the mutant, when compared to the wild-type, produces only about onethird of the cyclic GMP.

(ii) Physiology. The lowered levels of cyclic GMP production by the mutant will have drastic consequences on phototransduction. At increasing intensities of ambient illumination, there will be a shift in the response-intensity curve to lower light intensities. Particularly, at bright light intensities, the insufficient cyclic GMP synthesis would drive the photoreceptor into a state of permanent photoexcitation and hyperpolarization. In keeping with this explanation, the affected individuals with the mutation suffer from a decrease in visual acuity, severe dyschromatopsia and photophobia during their first decade of life (38). The cone dysfunction becomes more progressive over the following decades.
Finally, the rod function is also affected resulting in loss of peripheral vision and progressive night blindness (38). Photophobia would result from the above-mentioned shift in the response-intensity curve. The progressive loss of cone function is probably the result of a permanent change in $\mathrm{Ca}^{2+}$-homeostasis due to the low cyclic GMP content and closure of the CNG channels.

Synapse-Linked Module. (i) Biochemistry. The retinal synaptic activity linked module in ROS-GC1 is regulated by $\mathrm{S} 100 \beta$ in a $\mathrm{Ca}^{2+}$-dependent manner (23-25). In contrast to the phototransduction-linked modules, the activity of the $\mathrm{S} 100 \beta$-regulated module is reduced in ERT $\rightarrow \mathrm{DCM}$. The reduction is over 3 -fold. Taking into account the reduced basal activity of the mutant, the enzyme in its saturated state produces cyclic GMP, which is only $5-8 \%$ of that produced by the wt-rROS-GC1. This indicates that the enzyme has virtually no synapse-related activity.

(ii) Physiology. That the ERT $\rightarrow$ DCM mutation, indeed, disrupts the retinal synaptic transmission is consistent with the clinical observations that certain CORD6-afflicted patients show negative electroretinograms (39).

Mechanistic Implications. At a basic level, this study reveals the critical role of aa E786, R787, and T788 in multiple facets of ROS-GC1 modulation. The basal activity of ROS-GC1, its regulation through the phototransductionand its synapse-linked modules are all altered with the ERT $\rightarrow$ DCM mutation. Yet, the region covering these residues is not involved in the direct binding of GCAPs or $\mathrm{S} 100 \beta(8)$. What is the role of this region in ROS-GC1 modulation? This study, for the first time, clearly establishes that these residues are critical in the dimerization of ROS$\mathrm{GC} 1$, and that this process mediates the activity of ROS- 

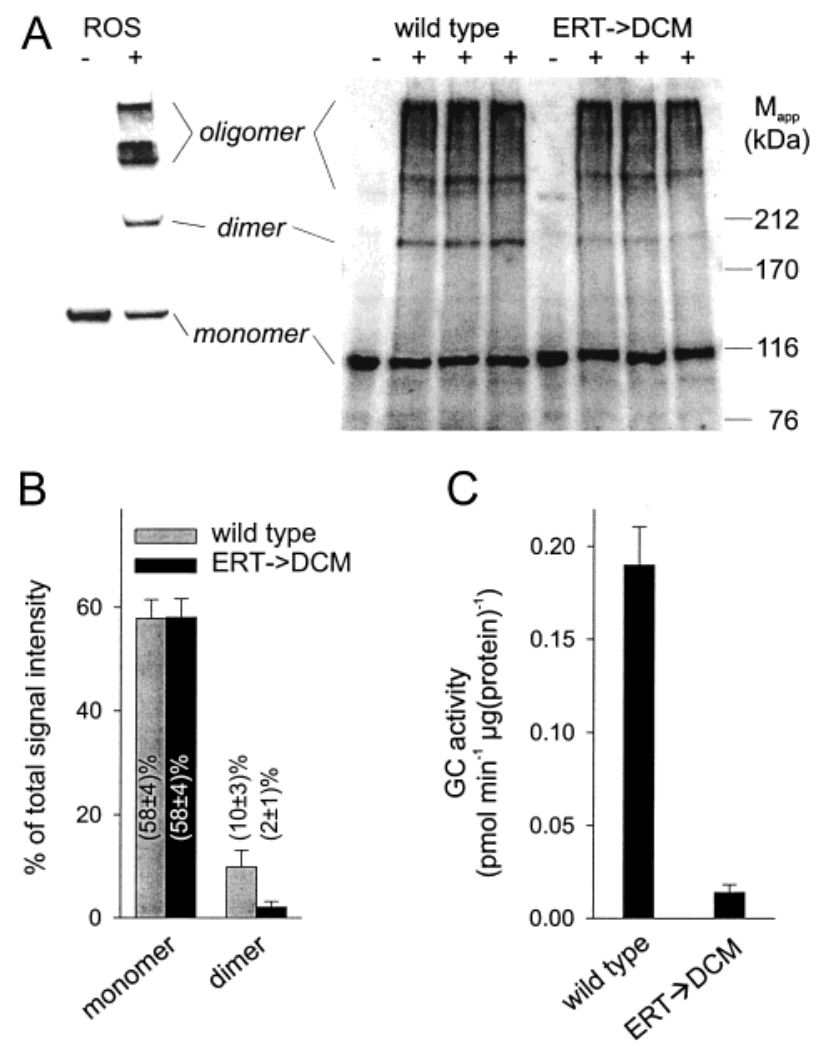

FIGURE 8: Cross-linking of native ROS-GC1, wt-rROS-GC1, and the ERT $\rightarrow$ DCM mutant. (A) Membranes of ROS or HEK293 cells expressing wt-rROS-GC1 or the ERT $\rightarrow$ DCM mutant were incubated in the absence $(-)$ or presence $(+)$ of $10 \mathrm{mM} \mathrm{BS}^{3}$; the reaction mixtures were analyzed by SDS-PAGE (left blot $7.5 \%$, right blot 5\%) and Western blotting. ROS-GC1 was detected with a polyclonal anti-ROS-GC1 antibody as described in Materials and Methods. (B) Relative intensities of monomer and dimer bands of the wt-rROS-GC1 and the E786D, R787C, and T788M mutant (100\% corresponds to the overall signal intensity within individual bands). (C) Guanylate cyclase activity of wtROS-GC1 and the $\mathrm{ERT} \rightarrow$ DCM mutant in HEK293 cell membranes preparations used in cross-linking experiments presented in panels A and B. The cyclase activity was assayed with $\mathrm{Mn}^{2+}$ as a cofactor. The results depicted in panels $\mathrm{A}-\mathrm{C}$ are representative for three experiments carried out with separate membrane preparations.

GC1 modules linked with phototransduction and synaptic activity.

Recent studies show that the catalysis of the cyclic GMP formation by ROS-GC1 occurs at a dimer interface (52) and that its activation by GCAPs or $\mathrm{S} 100 \beta$ involves dimerization step $(29,30)$. Thus, ROS-GC1 requires dimerization for effective catalytic activity $(29,30)$. A putative dimerization domain was proposed based purely on sequence features (9). The present study shows that the aa E786, R787, and T788 are critical for the dimerization of ROS-GC1. The findings demonstrate that the ERT $\rightarrow$ DCM mutation lowers the basal cyclase activity of the mutant and also disturbs its dimerization. This disruption is associated with lowered basal activity of ROS-GC1. Although the resultant mutant is hyperresponsive to GCAP1, the net cyclic GMP synthesized by this mutant is only one-third of that by the wild-type. These results show that the ERT domain is important for dimerization, its disruption interferes with the dimerization process, and the presence of GCAP1 can partially optimize the dimer interface, but cannot fully compensate for the disruption. These conclusions are reinforced by the previ-

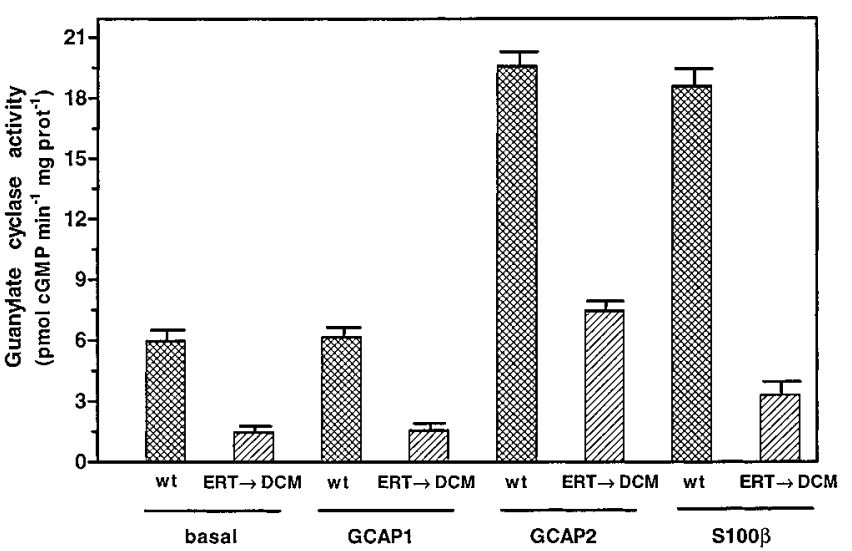

FIGURE 9: Guanylate cyclase activity of the fragment corresponding to amino acid residues $733-1054$ of wt-rROS-GC1 and of the ERT $\rightarrow$ DCM mutant. The fragments were expressed in bacterial cells and purified as described in Materials and Methods. The purified protein was assayed for guanylate cyclase activity with or without GCAP1, GCAP2, or $\mathrm{S} 100 \beta$ at appropriate $\mathrm{Ca}^{2+}$ concentrations. The experiment was repeated two times. The presented results are from one experiment done in triplicate.
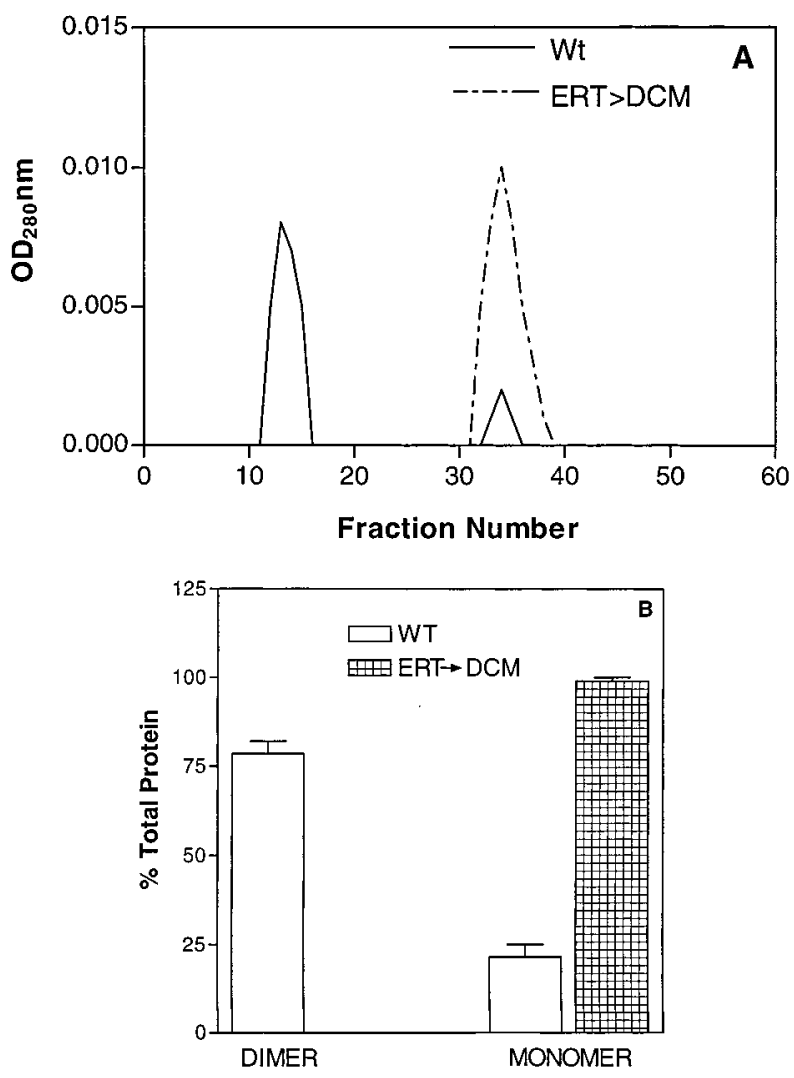

FIGURE 10: Gel-filtration chromatography. The fragments corresponding to amino acid residues 733-1054 of wt-rROS-GC1 and of the ERT $\rightarrow$ DCM mutant were expressed in bacterial cells and purified as described in Materials and Methods. These were analyzed by FPLC using Superdex-75 column. The elution was monitored by measuring absorbance at $280 \mathrm{~nm}$ (A). Quantitation of the peak was done through integration of the area under the peak after subtraction of the baseline (B).

ously published study on the R787C mutant (8). A similar lowering of the basal activity is observed as a result of this mutation. The mutant is hyperresponsive to GCAP1 and the net cyclic GMP production in the presence of GCAP1, is comparable to that of the wild-type. Thus, the defect in dimerization of ROS-GC1 due to the R787C mutation can 
be fully compensated by the presence of GCAP1, which promotes optimal dimer interface. No such compensation can occur if the two flanking residues, E786 and T788, are also mutated.

With respect to GCAP2 and $\mathrm{S} 100 \beta$, the maximal cyclic GMP synthesized by the R787C and the ERT $\rightarrow$ DCM mutant is significantly lower than that by the wild-type. This indicates that the transduction steps involved in GCAP2 and $\mathrm{S} 100 \beta$ signaling are distinct from those involved in GCAP1 signaling. One possible explanation is that these modulators bind to different sites on ROS-GC1 $(22,23,27)$ and cannot compensate for the altered dimerizing ability of the mutants.

\section{CONCLUSIONS}

CORD6 is a heterogeneous disease of the cones and rods that is caused by the mutations in ROS-GC1 gene. The disease phenotype of the ERT $\rightarrow$ DCM mutation, the subject of this study, is impaired vision. Knowledge of the biochemistry and functioning of the phototransduction- and synapselinked modules has allowed an incisive analysis of the effect of this mutation on ROS-GC1 modulation. Important insights into the biochemical and physiological aspects of ROS-GC1 function have been gained and a unifying mechanistic theme has been identified, which explains the disease phenotype based on the molecular alterations of enzyme function.

\section{ACKNOWLEDGMENT}

We thank our laboratory colleagues Anuradha Krishnan for Western blot experiments and Joan Sharma for help in the preparation of the manuscript.

\section{REFERENCES}

1. Pugh, E. N., Jr., Duda, T., Sitaramayya, A., and Sharma, R. K. (1997) Biosci. Rep. 17, 429-473.

2. Kaupp, U. B. (1995) Curr. Opin. Neurobiol. 5, 434-442.

3. Margulis, A., Goraczniak, R. M., Duda, T., Sharma, R. K., and Sitaramayya, A. (1993) Biochem. Biophys. Res. Commun. 194, 855-861.

4. Koch, K.-W., Stecher, P., and Kellner, R. (1994) Eur. J. Biochem. 222, 589-595.

5. Camuzat, A., Rozet, J.-M., Dollfus, H., Gerber, S., Perrault, I., Weissenbach, J., Munnich, A., and Kaplan, J. (1996) Hum. Genet. 97, 798-801

6. Semple-Rowland, S. L., Lee, N. R., Van Hooser, J. P., Palczewski, K., and Baehr, W. (1998) Proc. Natl. Acad. Sci. U.S.A. 95, 1271-1276.

7. Duda, T., Venkataraman, V., Goraczniak, R. M., Lange, C., Koch, K.-W., and Sharma, R. K. (1999) Biochemistry 38, 509-515.

8. Duda, T., Krishnan, A., Venkataraman, V., Lange, C., Koch, K.-W., and Sharma, R. K. (1999) Biochemistry 38, 1391213919.

9. Tucker, C. L., Woodcock, S. C., Kelsell, R. E., Ramamurthy, V., Hunt, D. M., and Hurley, J. B. (1999) Proc. Natl. Acad. Sci. U.S.A. 96, 9039-9044.

10. Goraczniak, R. M., Duda, T., Sitaramayya, A., and Sharma, R. K. (1994) Biochem. J. 302, 455-461.

11. Venkataraman, V., Nagele, R., Duda, T., and Sharma, R. K. (2000) Biochemistry 39, 6042-6052.

12. Yang, R. B., Foster, D. C., Garbers, D. L., and Fulle, H.-J. (1995) Proc. Natl. Acad. Sci. U.S.A. 92, 602-606.

13. Shyjan, A. W., de Sauvage, F. J., Gillett, N. A., Goeddel, D. V., and Lowe, D. G. (1992) Neuron 9, 727-737.

14. Lowe, D. G., Dizhoor, A. M., Liu, K., Gu, Q., Spencer, M., Laura, R., Lu, L., and Hurley, J. B. (1995) Proc. Natl. Acad. Sci. U.S.A. 92, 5535-5539.
15. Goraczniak, R. M., Duda, T., and Sharma, R. K. (1997) Biochem. Biophys. Res. Commun. 243, 666-670.

16. Duda, T., Goraczniak, R. M., Surgucheva, I., RudnickaNawrot, M., Gorczyca, W. A., Palczewski, K., Baehr, W., and Sharma, R. K. (1996) Biochemistry 35, 8478-8482.

17. Gorczyca, W. A., Gray-Keller, M. P., Detwiler, P. B., and Palczewski, K. (1994) Proc. Natl. Acad. Sci. U.S.A. 91, 40144018.

18. Palczewski, K., Subbaraya, I., Gorczyca, W. A., Helekar, B S., Ruiz, C. C., Ohguro, H., Huang, J., Zao, X., Crabb, J. P., Johnson, R. S., Walsh, K. A., Gray-Keller, M. P., Detwiler, P., and Baehr, W. (1994) Neuron 13, 395-404.

19. Frins, S., Bonigk, W., Muller, F., Kellner, R., and Koch, K.W. (1996) J. Biol. Chem. 271, 8022-8027.

20. Dizhoor, A. M., Lowe, D. G., Olshevskaya, E. O., Laura, R. P., and Hurley, J. B. (1994) Neuron 12, 1345-1352.

21. Dizhoor, A. M., Olshevskaya, E. O., Henzel, W. J., Wong, S. C., Stults, J. T., Ankoudinova, I., and Hurley, J. B. (1995) J. Biol. Chem. 270, 25200-25206.

22. Krishnan, A., Goraczniak, R. M., Duda, T., and Sharma, R. K. (1998) Mol. Cell. Biochem. 178, 251-259.

23. Duda, T., Goraczniak, R. M., and Sharma, R. K. (1996) Biochemistry 35, 6263-6266.

24. Margulis, A., Pozdnyakov, N., and Sitaramayya, A. (1996) Biochem. Biophys. Res. Commun. 218, 243-247.

25. Pozdnyakov, N., Goraczniak, R. M., Margulis, A., Duda, T., Sharma, R. K., Yoshida, A., and Sitaramayya, A. (1997) Biochemistry 36, 14159-14166.

26. Kumar, V. D., Vijay-Kumar, S., Krishnan, A., Duda, T., and Sharma, R. K. (1999) Biochemistry 38, 12614-12620.

27. Lange, C., Duda, T., Beyermann, M., Sharma, R. K., and Koch, K.-W. (1999) FEBS Lett. 460, 27-31.

28. Duda, T., Goraczniak, R. M., Pozdnyakov, N., Sitaramayya, A., and Sharma, R. K. (1998) Biochem. Biophys. Res. Commun. 242, 118-122.

29. Hao, Y., Olshevskaya, E., Duda, T., Seno, K., Hayashi, F., Sharma, R. K., Dizhoor, A. M., and Yamazaki, A. (1999) J. Biol. Chem. 274, 15547-15555.

30. Olshevskaya, E. V., Ermilov, A. N., and Dizhoor, A. M. (1999) J. Biol. Chem. 274, 25583-25587.

31. Duda, T., Venkataraman, V., Krishnan, A., and Sharma, R. K. (1998) Mol. Cell. Biochem. 189, 63-70.

32. Johnston, J. P., Farhangfar, F., Aparicio, J. G., Nam, S. H., and Applebury, M. (1997) Gene 193, 219-227.

33. Yang, R. B., Fulle, H.-J., and Garbers, D. L. (1996) Genomics 31, 367-372.

34. Perrault, I., Rozet, J.-.M., Calvas, P., Gerber, S., Camuzat, A., Dollfus, H., Chatelin, S., Souied, E., Ghazi, I., Leowski, C., Bonnemaison, M., Le Paslier, D., Frezal, J., Dufier, J. L., Pittler, S., Munnich, A., and Kaplan, J. (1996) Nat. Genet. 14, 461-464.

35. Camuzat, A., Rozet, J.-M., Dollfus, H., Gerber, S., Perrault, I., Weissenbach, J., Munnich, A., and Kaplan, J. (1996) Hum. Genet. 97, 798-801.

36. Rozet, J. M., Perrault, I., Gerber, S., Ducroq, D., Souied, E., Munnich, A., and Kaplan, J. (2000) Invest. Ophthal. Vis. Sci. 41, S533.

37. Perrault, I., Rozet, J.-M., Gerber, S., Kelsell, R. E., Souied, E., Cabot, A., Hunt, D. M., Munnich, A., and Kaplan, J. (1998) Am. J. Hum. Genet. 63, 651-654.

38. Kelsell, R. E., Gregory-Evans, K., Payne, A. M., Perrault, I., Kaplan, J., Yang, R.-B., Garbers, D. L., Bird, A. C., Moore, A. T., and Hunt, D. M. (1998) Hum. Mol. Genet. 7, 11791184.

39. Gregory-Evans, K., Kelsell, R. E., Gregory-Evans, C. Y., Downes, S. M., Fitzke, F. W., Holder, G. E., Simunovic, M. S., Mollon, J. D., Taylor, R., Hunt, D. M., Bird, A. C., and Moore, A. T. (2000) Ophthalmology 107, 55-61.

40. Weigell-Weber, M., Fokstuen, S., Török, B., Niemeyer, G., Schinzel, A., and Hergersberg, M. (2000) Arch. Ophthalmol. 118,300 . 
41. Goraczniak, R. M., Duda, T., and Sharma, R. K. (1998) Biochem. Biophys. Res. Commun. 245, 447-453.

42. Sambrook, M. J., Fritsch, E. F., and Maniatis, T. (1989) Molecular Cloning: A Laboratory Manual, Cold Spring Harbor, Plainview, New York.

43. Dhallan, R. S., Yau, K. W., Schrader, K. A., and Reed, R. R. (1990) Nature 347, 184-187.

44. Kaplan, R. S., and Pedresen, P. L. (1985) Anal. Biochem. 150, 97-104.

45. Nambi, P., Aiyar, N. V., Roberts, A. N., and Sharma, R. K. (1982) Endocrinology 111, 196-200.

46. Schrem, A., Lange, C., Beyermann, M., and Koch, K.-W. (1999) J. Biol. Chem. 274, 6244-6249.
47. Laura, R., Dizhoor, A. M., and Hurley, J. B. (1996) J. Biol. Chem. 271, 11646-11651.

48. Thorpe, D. S., Niu, S., and Morkin, E. (1991) Biochem. Biophys. Res. Commun. 180, 538-533.

49. Wilson, E. M., and Chinkers, M. (1995) Biochemistry 34, 4696-4701.

50. Yau, K. W. (1994) Invest. Ophthalmol. Visual Sci. 35, 9-32.

51. Lagnado, L., Cervetto, L., and McNaughton, P. A. (1992) J. Physiol. 455, 111-142.

52. Liu, Y., Ruoho, A. E., Rao, V. D., and Hurley, J. H. (1997) Proc. Natl. Acad. Sci. U.S.A. 94, 13414-13419.

BI001514D 